\title{
Hamartoma de glándulas de Brunner y anisakiasis: ¿una asociación etiológica?
}

\author{
J. J. VILA COSTAS, J. M. MARTÍNEZ-PEÑUELA VIRSEDA' J. M. ZOZAYA \\ URMENETA, M. MANRIQUE CELADA ${ }^{1}$, R. AZNAREZ BARRIO, E. ZOZAYA \\ ÁLVAREZ ${ }^{1}$, F. BORDA CELAYA \\ Servicio de Aparato Digestivo y de 'Anatomía Patológica. Hospital de Navarra. \\ Pamplona, Navarra
}

\author{
BRUNNER'S GLAND HAMARTOMA AND ANISAKIASIS: AN ETHIO \\ LOGIC ASSOCIATION?
}

\begin{abstract}
RESUMEN
El hamartoma de glándulas de Brunner es un raro tumor duodenal localizado con mayor frecuencia a nivel de la primera porción, que si bien puede ser asintomático no es raro que produzca cuadros de hemorragia digestiva u obstrucción intestinal. Su diagnóstico se realiza por gastroscopia o estudio digestivo baritado y su tratamiento consiste en la resección endoscópica o quirúrgica, con muy buen pronóstico. Presentamos el caso de una mujer de 59 años que acude al hospital con un cuadro clínico de hemorragia digestiva alta presentando en la endoscopia realizada una úlcera sobre un pólipo en bulbo duodenal. Se realizó polipectomía correspondiendo en el estudio histológico a un hamartoma de glándulas de Brunner en cuyo interior aparecía un granuloma parasitario. La determinación de IgE para Anisakis así como los test cutáneos fueron positivos. La asociación de hamartoma de glándulas de Brunner y granuloma parasitario por Anisakis no se había descrito nunca.
\end{abstract}

PALABRAS CLAVE: Anisakis. Hamartoma de glándulas de Brunner. Hemorragia gastrointestinal. Enfermedad parasitaria intestinal.

\begin{abstract}
Brunner's gland hamartoma is a rare duodenal tumor generally localized in the duodenal bulb. Normally assymptomatic, it might cause upper gastrointestinal bleeding or intestinal obstruction. The diagnosis is based on upper gastrointestinal endoscopic or barium examination findings, and its treatment includes surgical or endoscopic ressection, with an optimum prognosis. We present the case of a 59-year-old woman who was admitted to the hospital with an upper gastrointestinal bleeding picture. Endoscopic examination showed an ulcerated polyp in duodenal bulb which was cut with polipectomy wire. Histological slides showed a parasitic granuloma within a Brunner's gland hamartoma. Skin prick test and specific IgE determination were positive for Anisakis. Up to our knowledge, this association has never been described before.
\end{abstract}

KEY WORDS: Anisakis. Brunner's glands hamartoma. Gastrointestinal hemorrhage. Parasitic intestinal diseases.

Vila Costas JJ, Martínez-Peñuela Virseda JM, Zozaya Urmeneta JM, Manrique Celada M, Aznarez Barrio R, Zozaya Alvarez E, Borda Celaya F. Hamartoma de glándulas de Brunner y anisakiasis: ¿una asociación etiológica? An Med Interna (Madrid) 2003; 20: 470-472.

\section{INTRODUCCIÓN}

El caso que nos ocupa corresponde a un raro caso de hemorragia digestiva alta en relación con una ulceración sobre un pólipo duodenal que histológicamente correspondía a un hamartoma de glándulas de Brunner, pero en el que se apreció la presencia de un granuloma parasitario. Los test diagnósticos realizados para para la detección de Anisakis fueron positivos. Los hamartomas de glándulas no son tumores muy frecuentes y cuando aparecen sí suelen estar ulcerados siendo causa conocida, aunque muy rara, de hemorragia digestiva alta.

El Anisakis es un nemátodo de la familia anisakidae, subfamilia anasikinae. Todas las infecciones en el hombre son causadas por larvas pertenecientes a esta subfamilia, que pue- den medir hasta $3 \mathrm{~cm}$ de largo y un milímetro o más de ancho y se encuentran en el tercer o cuarto estadío del desarrollo cuando parasitan al hombre. Los Anisakis no alcanzan una madurez sexual en huéspedes aberrantes, por lo que no se reproducen en el hombre, que es un huésped definitivo que se infecta tras la ingesta de pescado marino crudo o poco cocinado (1).

\section{CASO APORTADO}

Se trata de una mujer de 59 años sin antecedentes de interés que acude al servicip de urgencias por un cuadro de malestar general, náuseas y un episodio de hematemesis unos minutos antes. En la

Trabajo aceptado: 17 de enero de 2003

Correspondencia: Juan José Vila Costas. Servicio de Aparato Digestivo. Hospital de Navarra. C/ Irunlarrea, 3. 31008 Pamplona (Navarra). e-mail: xoanxose@hotmail.com 
exploración física presentaba buen estado general, con tension arterial de 130/90 una frecuencia cardíaca de 128 latidos por minuto y ligera palidez muco-cutánea. A la auscultación cardio-pulmonar presentaba la ya conocida taquicardia. La exploración abdominal era normal y en el tacto rectal se objetivó la presencia de melenas. En la analítica realizada presentaba un hematocrito de $32,4 \%$, hemoglobina: $11 \mathrm{~g} / \mathrm{dL}$, hematíes: $3.440 .000 \mu \mathrm{L}$, VCM: $94,2 \mathrm{fL}$, plaquetas: $162.000 / \mu \mathrm{L}$, leucocitos: $16.000 / \mu \mathrm{L}$, con 11.400 netrófilos $/ \mu \mathrm{L}, 3.900$ linfocitos $/ \mu \mathrm{L}$ y $0,1 \times 10^{9}$ eosinófilos. Actividad de protrombina: $73 \%$, APTT: 23 seg., fibrinógeno: $198 \mathrm{mg} / \mathrm{dL}$. Urea: $120 \mathrm{mg} / \mathrm{dL}$, glucosa: $148 \mathrm{mg} / \mathrm{dL}$, creatinina: $0,8 \mathrm{mg} / \mathrm{dL}$, siendo el resto del perfil bioquímico normal. Se realizó una gastroscopia de urgencia en la que se objetivaron restos hemáticos frescos en el estómago, presentando en bulbo duodenal un gran pólipo $(1,8 \times 1,8 \mathrm{~cm})$ a nivel de cara posteroinferior con una úlcera apical y sangrado activo en sábana (Fig. 1). El esófago, estómago y segunda porción duodenal fueron normales, no apreciando ninguna otra lesión potencialmente sangrante.

Se realizó una resección con asa de polipectomía resolviéndose el cuadro hemorrágico sin incidencias.

El examen macroscópico mostró un pólipo marrón, con superficie nodular con un diámetro de $1,8 \mathrm{~cm}$ y una base de $1,3 \mathrm{~cm}$. Al corte presentaba una consistencia blanda y la presencia de una masa quística en su interior de color beige (Fig. 2).

En el examen histológico se apreció una proliferación de las estructuras glandulares acinares con secreción mucosa en forma de formaciones ductales dilatadas y ocasionalmente microquísticas correspondientes a glándulas de Brunner dilatadas que se continua-

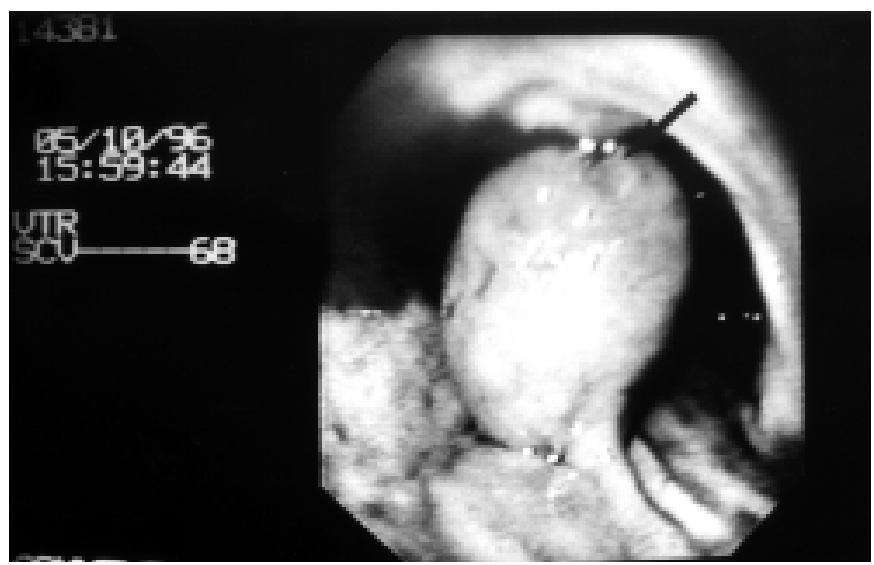

Fig. 1. Imagen endoscópica en la que se aprecia la formación polipoidea descrita en la que es Ilamativa la úlcera apical (flecha).

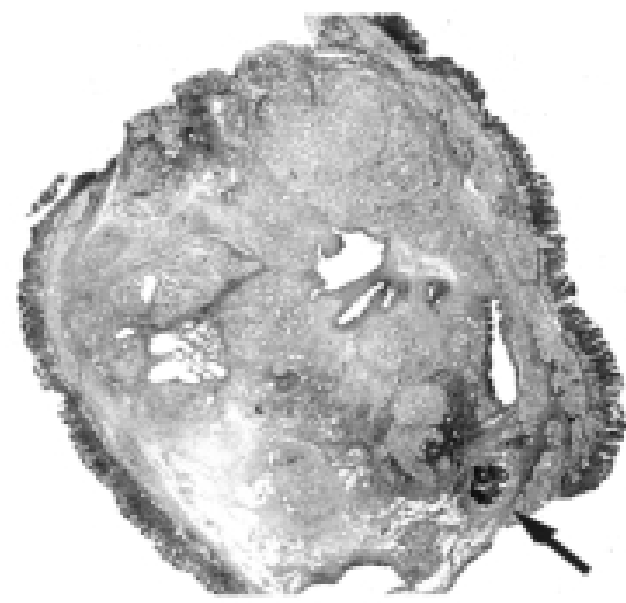

Fig. 2. $1,8 \times 2 \mathrm{~cm}$. Hamartoma de glándulas de Brunner en cuyo interior se puede apreciar el granuloma parasitario. ban con las glándulas de Brunner adyacentes duodenales. Presentaba además zonas estromales fibrosas con la presencia de fascículos de músculo liso. Llamó la atención la presencia de un granuloma inflamatorio con células epitelioides en la periferia y abundantes eosinófilos. En el centro del pólipo era obvia la presencia de necrosis y fragmentos de un material eosinofílico. No se apreciaron signos de malignidad.

Para completar el estudio diagnóstico, ante la sospecha de infestación por Anisakis, se realizó un prick test cutáneo standard para Anisakis y la determinación de anticuerpos IgE específicos mediante el método RAST, siendo ambos claramente positivos (test cutáneo: $3 \times 3 \mathrm{~mm}$, IgE: 4,99 KU/L). El RAST fue negativo para otros parásitos como Ascaris y Echinoccocus.

El diagnóstico final realizado fue de hemorragia digestiva alta en relación con hamartoma de glándulas de Brunner ulcerado con infección antigua por Anisakis.

En su evolución posterior la paciente presentó una anemización importante con valores de $\mathrm{Hgb}:$ 8,6 gr/dL, hematocrito: 26,4\%, hematíes: 2.780 .000 , urea: $61 \mathrm{mg} / \mathrm{dL}$; todo ello en relación con el sangrado inicial, no presentando signos de resangrado. Esta anemización obligó a la transfusión de dos unidades de hematíes. Buena evolución posterior siendo dada el alta estando asintomática nueve días después de su ingreso hospitalario.

\section{DISCUSIÓN}

La etiopatogenia del hamartoma de glándulas de Brunner no está clara y ha sido asociado a estados de hiperacidez (2). Son más frecuentes en adultos y suelen ser pólipos pedunculados y localizarse en la primera porción duodenal a nivel de cara posterior, con un tamaño que oscila entre 1 y $6 \mathrm{~cm}$. Su presentación clínica es también variable: pueden ser asintomáticos o causar hemorragia u obstrucción, siendo los sangrantes más frecuentes más allá de la primera porción duodenal (3). La ausencia de displasia es una característica de estos tumores lo que nos lleva a nosotros y otros autores (3) a clasificarlos como hamartomas y no adenomas que es su clásica denominación.

La Anisakiasis es un diagnóstico cada vez más frecuente en los países industrializados (1), probablemente en relación con los cambios en el hábito alimentario (4) y la mejora de los métodos diagnósticos desarrollada en los últimos años $(5,6)$. Dos de esas técnicas son las utilizadas en este caso: la detección de los niveles de IgE antiAnisakis en suero mediante el método RAST y el prick test cutáneo basado en la sensibilización a antígenos de Anisakis, ambas perfectamente validadas en la literatura (7). En el hombre se ha descrito la infección por los géneros Anisakis y Pseudoterranova, ambos pertenecientes a la subfamilia Anisakinae (4). Anisakis causa una infección invasiva fijándose a través de su cabeza y penetrando en la pared intestinal, siendo su presentación clínica muy variable en función de la localización: la parasitación gástrica suele producir úlceras con dolor abdominal y vómitos (4), ocasionalmente hemáticos; en el intestino delgado el cuadro clínico suele similar una apendicitis o una enteritis regional, pudiendo producirse una obstrucción intestinal (8). La mayoría de estos casos son de difícil diagnóstico debido a que simulan otras entidades clínicas como gastritis, apendicitis, siendo imposible en muchos casos encontrar el parásito que no es expulsado en las heces. Otra posible presentación clínica de la parasitación por Anisakis son los procesos alérgicos, desde urticaria hasta shock anafiláctico (9). 
Si bien los hallazgos macroscópicos no son específicos, microscópicamente la anisakiasis se caracteriza en estadios precoces por la presencia de un edema intersticial difuso asociado a un infiltrado inflamatorio con la presencia de gran cantidad de eosin6filos además de neutr6filos, linfocitos, monocitos y células plasmáticas llegando a formar abscesos eosinoMicos. Las lesiones más avanzadas, entre las que se podria incluir el caso descrito, muestran granulomas de células epitelioides con células gigantes de cuerpo extraño. Esta respuesta inflamatoria se acompaña de la destrucci6n del parásito, como parece haber ocurrido en este caso. Por tanto, los parásitos bien conservados se pueden apreciar en los estadios precoces, mientras que los granulomas indicativos de infecci6n antigua muestran solo fragmentos distorsionados de cuticula (4). A medida que la respuesta inflamatoria destruye el parásito, los rasgos caracteristicos del mismo van gradualmente desapareciendo y su identificacion se torna imposible como en el caso que nos ocupa, en el que la infecci6n por Ani- sakis se corresponde a una infecci6n de larga evoluci6n. En nuestro caso la ausencia de eosinofilia periférica podria llevarnos a pensar un origen distinto para el granuloma, si embargo es posible la ausencia de eosinofilia periférica en casos de afectaci6n intestinal localizada (10).Nuestra paciente no presentaba historia de reacciones alérgicas ni otros antecedentes de interés. Negó ingesta de pescado en las horas previas al ingreso, pero sí admitió el consumo frecuente de pescado, y como ya se ha comentado la lesión histológica corresponde a una infección por Anisakis de larga evolución,

En nuestra opinión la presencia del granuloma parasitario en el interior del hamartoma es un hallazgo incidental. No es del todo descartable que la parasitación por el Anisakis haya constituido el estímulo que haya provocado el desarrollo del hamartoma de glándulas de Brunner, aunque esto no pasa de ser una hipótesis sin datos en la literatura que la apoyen ya que es esta la primera vez que esta asociación es descrita en la literatura consultada.

\section{Bibliografía}

1. Mira Gutierrez J, García Martos P, Hilario Madrid LM, Rodríguez Iglesias MA. Anisakiasis, una parasitosis emergente en nuestro medio. Rev Clin Esp 1995; 195: 51-54.

2. De-Angelwas G, Villanici V, Lovotti D, et al. Hamartomatous polyps of Brunner's gland: presentation of 2 cases. Review of the literature. Minerva Chir 1989; 44: 1761-6.

3. Levine JA, Burgart LJ, Batts KP, Wang KK. Brunner's gland hamartomas: clinical presentation and pathological features of 27 cases. Am J Gastroenterol 1995; 90 (2): 290-4.

4. Tuñon T,Zozaya E,TabarAI,G Dorronsoro ML,Gomez B,Valenti C. Eosinophilic enteritis due to anisakis: a call for pathologists' attention. Int J Surg Pathol 1997; 5 (3/4): 69-76.

5. Del Pozo MD, Moneo Y, Fernández de Corres L, Audicana MT, Muñoz D, Fernández E, Navarro JA, García M. Laboratory determinations in Anisakis simplex allergy. J Allergy Clin Immunol 1996; 97: 977-984.
6. Kijewska A, Slominska M, Wegrzyn G, Rokicki J. A PCR-RFLP assay for identification of Anisakis simplex from different geographical regions. Mol Cell Probes 2000; 14 (6): 349-54.

7. Lorenzo S, Iglesias R, Leiro J, Ubeira FM, Ansotegui I, Garcia M, Fernández de Corres L. Usefulness of currently available methods for the diagnosis of Anisakis simplex allergy. Allergy 2000; 55 (7): 627-33.

8. Kim LS, Lee YH, Kim S, Park HR, Cho SY. A case of anisakiasis causing intestinal obstruction. Kisaengchunghak Chapchi 1991; 29: 93-6.

9. García-Labairu C, Alonso-Martínez JL, Martinez-Echeverría A, RubioVela T, Zozaya-Urmeneta JM. Asymptomatic gastroduodenal anisakiasis as the cause of anaphylaxix. Eur J Gastroenterol Hepatol 1999; 11 (7): 785-7.

10. Talley NJ, Shorter RG, Phillips SF, Zinsmeister AR. Eosinophilic gastroenteritis: a clinicopathological study of patients with disease of the mucosa, muscle layer, and subserosal tissues. Gut 1990; 31: 54-58. 